\title{
Electrochemical dearomative 2,3-difunctionalization of indoles
}

\author{
Ju Wu, Yingchao Dou, Régis Guillot, Cyrille Kouklovsky, Guillaume Vincent* \\ Institut de Chimie Moléculaire et des Matériaux d'Orsay (ICMMO, UMR 8182), Equipe MSMT, Univ. Paris Sud, \\ CNRS, Université Paris-Saclay, 15, rue Georges Clémenceau, 91405 Orsay, Cedex, France.
}

Supporting Information Placeholder

\begin{abstract}
We report the use of electrochemistry to perform a direct oxidative dearomatization of indoles leading to 2,3-dialkoxy or 2,3-diazido indolines under undivided conditions at a constant current. This operationally simple electrooxidative procedure avoids the use of an external oxidant and displays an excellent functional group compatibility. The formation of the two $\mathrm{C}-\mathrm{O}$ or $\mathrm{C}-\mathrm{N}$ bonds is believed to arise from the oxidation of the indoles into radical cation intermediates.
\end{abstract}

The direct difunctionalization of double bonds is a field of intense synthetic efforts since it allows the formation of two new bonds via the introduction of two functional groups. Indeed, such transformation of alkenes or styrenes is very well documented and usually requires the use of an external stoichiometric oxidant. ${ }^{1}$ In the last years, electrochemistry has been rediscovered to be a powerful sustainable synthetic tool in organic chemistry, thanks to the recent discovery of selective reactions and to easy-to handle apparatus or electrolysis set-ups which render electrochemistry accessible to all organic chemists. ${ }^{2}$ Along with the bloom of photoredox catalysis, this rebirth of electrosynthesis has enable the development of external oxidant-free methods for the highly efficient and selective difunctionalization of alkenes in mild conditions which usually involves the generation of a radical intermediate which adds to the alkene (Scheme 1).3 Performing the direct functionalization of a double bond imbedded in an aromatic heterocycle results in a more challenging dearomatization process 4 and provides three-dimensional chemicals of high added value. 5 It is particularly interesting to perform such dearomatization reactions on the indole nucleus due to the biological importance of this heterocycle. A myriad of dearomative difunctionalizations of indoles are known, ${ }^{6}$ including our own work, 7 which generally require the use of a strong oxidizing agent. In contrast, electrochemistry has been scarcely explored in dearomatization reactions. $3^{\mathrm{a}, \mathrm{h}, \mathrm{l}, 8,9}$ In this context, we would like to report the electrochemical straightforward dearomatization of indoles with the formation of two carbon-heteroatom bonds (C-O or C-N).

In the past 6 years, we have investigated the reactivity of $\mathrm{N}$ acyl indoles in dearomatization reactions including oxidative couplings with nucleophiles. ${ }^{\mathrm{c}-\mathrm{f}}$ Following our synthesis of benzofuro[3,2- $b$ ] indolines via a $(3+2)$ annulation between $\mathrm{N}$ acyl indoles and phenols mediated by DDQ and $\mathrm{FeCl}_{3},{ }^{7 \mathrm{c}}$ Lei and co-workers described an electrochemical version of our reaction with improved yields and an extended scope. ${ }^{8 a}$ In line with our interest in dearomatization reactions of $\mathrm{N}$-acyl indoles, it inspired us to explore the electrochemical oxidation of $\mathrm{N}$-acyl indoles in presence of nucleophiles through, presumably, the oxidation of the indole nucleus into a radical cation which is, mechanistically, in contrast to most of the electrochemical difunctionalization of alkenes (Scheme 1). .a,c $^{8}$

\section{Scheme 1. Electrochemical difunctionalization of al- kenes and heteroarenes.}

Electrochemical difunctionalization of alkenes

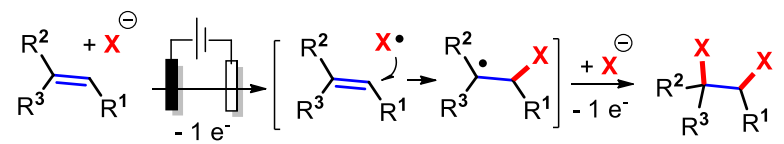

Electrochemical dearomatization of indoles (this approach)

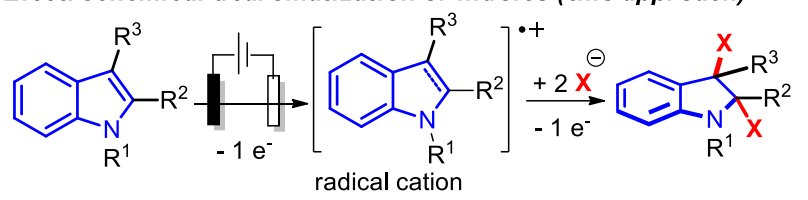

As a proof-of-principal experiment, we studied the 2,3-bismethoxylation of $\mathrm{N}$-Ac skatole $1 \mathrm{a}$ (Scheme 2, A).9,10 The electrolysis of $1 \mathrm{a}$ at a constant current of $8.9 \mathrm{~mA} / \mathrm{cm}^{2}$ with a graphite anode and a platinum cathode in a 1:1 mixture of $\mathrm{MeOH}$ and acetonitrile in an undivided cell and $n-\mathrm{Bu}_{4} \mathrm{NBF}_{4}$ as the electrolyte at room temperature, yielded the expected 2,3-dimethoxyindoline $\mathbf{2 a}$ in $77 \%$ yield as a 9:1 mixture of diasteroisomers in favor of the trans addition of the two methoxy groups. The use of $5 \mathrm{~mol} \%$ of TEMPO allowed us to improve the yield to $89 \%$ and to avoid decomposition of $\mathbf{1 a}$. It was possible to implement this transformation on gram scale. The dialkoxylation could also be performed in ethanol leading to $\mathbf{2 b}$ or with functionalized alcohols such as allyl alcohol, cyclopropyl methanol, homopropargyl alcohol and ethylene glycol to yield indolines $\mathbf{2 c - 2 f}$. The electron-withdrawing substituent on the nitrogen of the indole was next evaluated and indolines 2g-j containing pivaloyl, formyl, benzoyl and tosyl groups were obtained. The nature of the substituents on the benzene ring was next scrutinized. The reaction tolerates electron-donating groups, halogens or electron-withdrawing groups at $\mathrm{C}_{5}$, C6 or $\mathrm{C}_{7}$ positions (2k-t). Indoline $\mathbf{2 u}$ was obtained efficiently from 2,3-unsubstituted-N-Ts-indole. The dearomative dimethoxylation reaction proceeds well with alkyl groups or phenyl substituents at the $C_{3}$ position $(\mathbf{2 v - z})$. More interestingly, the mild conditions of the reaction allow to preserve 
functional groups on the $\mathrm{C}_{3}$-side chain: cyano-containing indoline $2 \mathbf{a a}$ and bromo-containing indoline $\mathbf{2 a b}$ were obtained without, respectively, hydrolysis or nucleophilic substitution by methanol. Impressively, dimethoxylation of a 3-cyclopropylindole could be performed without noticeable opening of the cyclopropyl group leading to cyclopropylindoline 2 ac.

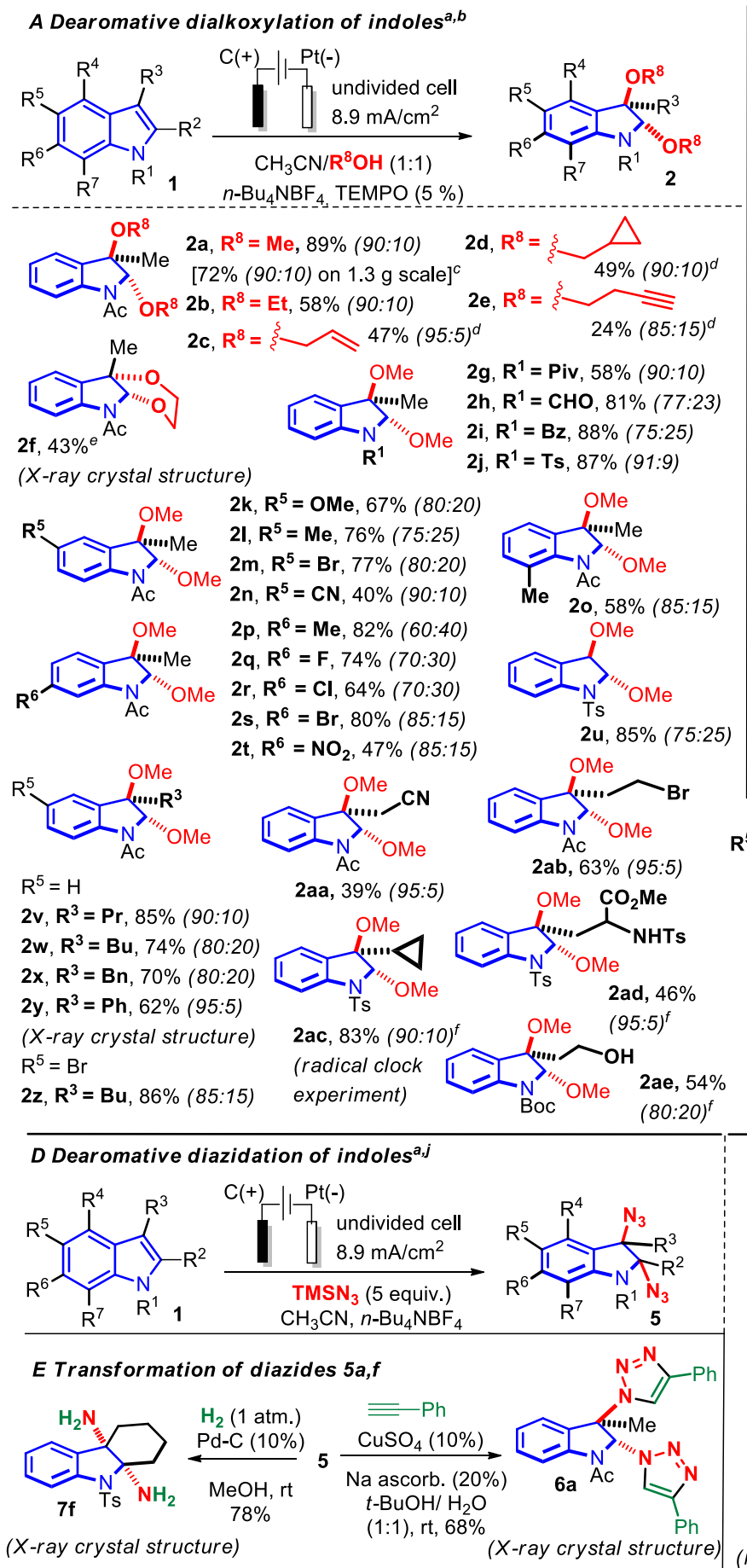

\section{Scheme 2. Electrolysis of indoles}

B Alpha-alkoxylation of 2,3-disubstituted indoles ${ }^{a, h}$
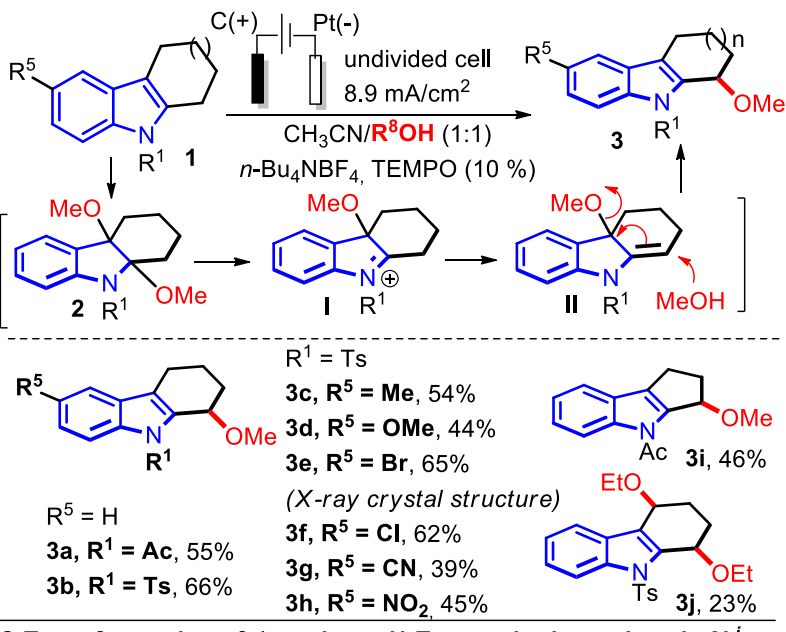

C Transformation of 1-methoxy-N-Ts-tetrahydrocarbazole $3 b^{i}$

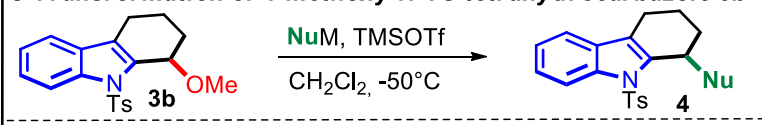

4a, $\mathrm{Nu}=\mathrm{N}_{3}, 90 \% \quad$ 4b, $\mathrm{Nu}=\mathrm{CN}, 86 \% \quad$ 4c, $\mathrm{Nu}=\mathrm{Allyl}, 81 \%$ from $\mathrm{TMSN}_{3}$ from TMSCN from AllylTMS

4d, $\mathrm{Nu}=$ 2,4,6-triOMePh, 78\% from 1,3,5-triOMePh

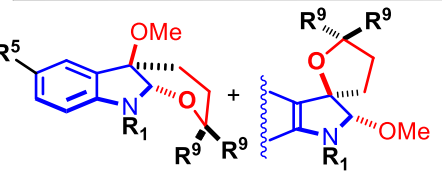

2af, $\mathbf{R}^{5}=\mathbf{H}, \mathrm{R}^{9}=\mathrm{H}, \mathrm{R}^{1}=\mathrm{CO}_{2} \mathrm{Et}, 72 \%, \mathrm{rr} 85 / 15^{f, g}$ 2ag, $\mathbf{R}^{5}=\mathbf{F}, \mathrm{R}^{9}=\mathrm{H}, \mathrm{R}^{1}=$ Boc, $57 \%$, rr $85 / 15^{f, g}$ 2ah, $\mathbf{R}^{5}=\mathbf{C N}, \mathrm{R}^{9}=\mathrm{H}, \mathrm{R}^{1}=$ Boc, $76 \%$, rr $90 / 10^{f, g}$ 2ai, $\mathrm{R}^{5}=\mathrm{H}, \mathbf{R}^{9}=\mathbf{M e}, \mathrm{R}^{1}=$ Boc, $72 \%$, rr 70/30 ${ }^{f, g}$ 2aj, $R^{5}=H, R^{9}=H, R^{1}=\sim$, $62 \%, r r 95 / 5^{g}$

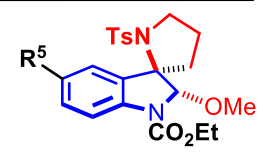

2ak, $\mathbf{R}^{5}=$ OMe $53 \%(95: 5)^{f}$ 2al, $\mathbf{R}^{5}=\mathbf{M e}$ $54 \%(95: 5)^{f}$ (X-ray crystal structure)

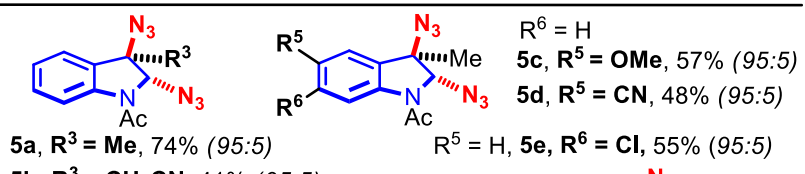
$\mathbf{5 b}, \mathbf{R}^{3}=\mathbf{C H}_{\mathbf{2}} \mathbf{C N}, 41 \%(95: 5)$

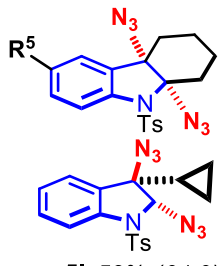

5I, $59 \%(91: 9)$ 5f, $\mathbf{R}^{\mathbf{5}}=\mathbf{H}, 70 \%(95: 5)$ $\mathbf{5 g}, \mathbf{R}^{\mathbf{5}}=\mathbf{O M e}, 56 \%(95: 5)$ 5h, $\mathbf{R}^{\mathbf{5}}=\mathbf{B r}, 79 \%(95: 5)$

$\mathbf{5 i}, \mathbf{R}^{\mathbf{5}}=\mathbf{C I}, \mathbf{7 4 \%}$ (95:5) 5j, $\mathbf{R}^{\mathbf{5}}=\mathbf{C N}, 59 \%(95: 5)$

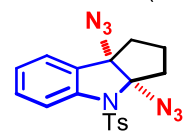

5k, 51\% (95:5)<smiles>[Mg]</smiles>

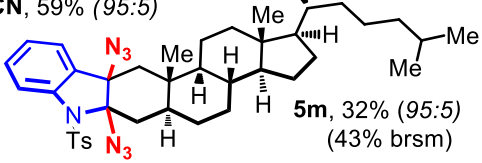

${ }^{a}$ Undivided cell, graphite-SK50 anode $(1.4 \mathrm{~cm} \times 0.8 \mathrm{~cm} \times 0.2 \mathrm{~cm}$ submerged), platinum plated cathode $(1.4 \mathrm{~cm} \times 0.8 \mathrm{~cm} \times 0.2 \mathrm{~cm}$ submerged), constant current of $10 \mathrm{~mA}\left(\mathrm{~J}=8.9 \mathrm{~mA} / \mathrm{cm}^{2}\right), 5 \mathrm{~mL}$ of solvent, room temperature; isolated yields (diastereomeric ratio) are indicated. ${ }^{b} \mathbf{1}(0.4 \mathrm{mmol}$ ), TEMPO (o.02 mmol), $n-\mathrm{Bu}_{4} \mathrm{NBF}_{4}(0.4 \mathrm{mmol}), \mathrm{R}^{8} \mathrm{OH} / \mathrm{CH}_{3} \mathrm{CN}(2.5 \mathrm{~mL} / 2.5 \mathrm{~mL}) ;{ }^{c}$ anode $(0.8 \mathrm{~cm} \times 3.4 \mathrm{~cm} \times 0.2 \mathrm{~cm}$ submerged), cathode (3.4 cm x o.8 $\mathrm{cm}$ x $0.2 \mathrm{~cm}$ submerged), constant current of $15 \mathrm{~mA}\left(\mathrm{~J}=5.5 \mathrm{~mA} / \mathrm{cm}^{2}\right), \mathbf{1}(8 \mathrm{mmol})$, TEMPO (o.0256 mmol), $n-\mathrm{Bu}_{4} \mathrm{NBF}_{4}(2 \mathrm{mmol}), \mathrm{MeOH} / \mathrm{CH}_{3} \mathrm{CN}(8$ $\mathrm{mL} / 8 \mathrm{~mL}){ }^{d}$ in AllylOH/CH${ }_{3} \mathrm{CN}(1 \mathrm{~mL} / 4 \mathrm{~mL})$ or cyclopropyl methanol/ $\mathrm{CH}_{3} \mathrm{CN}(1.5 \mathrm{~mL} / 3.5 \mathrm{~mL})$ or homopropargyl alcohol/CH${ }_{3} \mathrm{CN}(1.5 \mathrm{~mL} / 3.5 \mathrm{~mL})$; ${ }^{e}$ in $\mathrm{OH}\left(\mathrm{CH}_{2}\right)_{2} \mathrm{OH} / \mathrm{DMF}(1.5 \mathrm{~mL} / 3.5 \mathrm{~mL}) ;{ }^{f}$ on $0.2 \mathrm{mmol}$ of $\mathbf{1} ;{ }^{g}$ regioisomeric ratio; ${ }^{h} \mathbf{1}(0.2 \mathrm{mmol})$, TEMPO $(0.03 \mathrm{mmol}), n-\mathrm{Bu}_{4} \mathrm{NBF}_{4}(0.2 \mathrm{mmol})$, $\mathrm{MeOH} / \mathrm{CH}_{3} \mathrm{CN}(2.5 \mathrm{~mL} / 2.5 \mathrm{~mL}) ;{ }^{i} 3$ (o.2 mmol), NuM (o.3 mmol), TMSOTf (o.04 mmol), $\left.\mathrm{CH}_{2} \mathrm{Cl}_{2}(2 \mathrm{~mL}),-50^{\circ} \mathrm{C} ;{ }^{j} \mathbf{1}_{(0.2} \mathrm{mmol}\right), \mathrm{TMSN}_{3}(1 \mathrm{mmol}), n-$ $\mathrm{Bu}_{4} \mathrm{NBF}_{4}$ (o.2 mmol), $\mathrm{CH}_{3} \mathrm{CN}(5 \mathrm{~mL})$. 
The dimethoxylated indolines $\mathbf{2 a d}$,ae were obtained from tryptophan or tryptophol derivatives, despite the presence of a nucleophilic entity on their $\mathrm{C}_{3}$-side chain. Adding one carbon to the $\mathrm{C}_{3}$-side chain led to intramolecular trapping by the nucleophile. In the case of alcohols, methoxy-tetrahydropyranoindolines 2af-aj were obtained as the major products via intermolecular addition of methanol at the $C_{3}$ position. In contrast, tosylamide-containing $C_{3}$-side chains led selectively to valuable trans-spirocyclic indolines $\mathbf{2 a k , a l , ~ p r e s u m a b l y ~ v i a ~ i n - ~}$ itial intramolecular trapping of the indole radical cation at $C_{3}$.

The reactivity of tetrahydroacarbazoles in the same oxidative conditions was then examined (Scheme 2, B). In contrast to 3-monosubstituted $\mathrm{N}$-acyl indoles, alpha-monomethoxylation occurred. ${ }^{11}$ This formal benzylic $\mathrm{C}-\mathrm{H}$ functionalization likely proceeds via the dearomative dimethoxylation of the $C_{2}=C_{3}$ bond followed by elimination of the methoxy at $C_{2}$ of 2 and isomerization of the iminium I into enamide intermediate II which could be attacked by methanol to yield 3 upon allylic nucleophilic substitution.9,11a-c Alpha-methoxy carbazoles were thus obtained with acetyl or tosyl groups on the nitrogen (3a,b) and electron-donating (3c,d), halogens (3e,f) or electron-withdrawing $(\mathbf{3 g}, \mathbf{h})$ groups on the benzene part. The reaction could also be extended to cyclopentaindole $3 \mathbf{i}$. Unfortunately, 2,3-dimethyl-N-Ts-indole was not a competent substrate. Surprisingly, with ethanol, two alkoxylations occurred on the two positions vicinal to the indole ring and diethoxyindoline zj was obtained. Methoxy-N-Ts-tetrahydrocarbazole $\mathbf{3} \mathbf{b}$ could be used as a platform to access molecular diversity. Addition of various nucleophiles leads to tetrahydrocarbazoles 4 substituted respectively by an azide (4a), a cyanide $(4 \mathbf{b})$, an allyl $(4 \mathbf{c})$ and an arene $(4 \mathbf{d})$ (Scheme $2, \mathrm{C}) .{ }^{11 \mathrm{c}}$

Next, we evaluated the possibility of forming two $\mathrm{C}-\mathrm{N}$ bonds instead of the $\mathrm{C}-\mathrm{O}$ bonds during the electrochemical oxidative dearomatization of indoles by replacing methanol by a nitrogen-containing reagent. ${ }^{\text {h }}$ During recent developments in diazidation of alkenes, very few examples of diazidation of indoles were reported using an external oxidant. ${ }^{12}$ Very recently, a powerful electrochemical general diazidation of alkenes with a manganese electrocatalyst was published in which only one example from a 2,3-unsubstituted indole is described.3a, Eventually, the electrolysis of N-Ac skatole in presence of trimethylsilyl azide led to 2,3-diazide indoline $5 \mathbf{a}$ with an excellent trans-diastereoselectivity (Scheme 2, D). This electrochemical diazidation reaction is compatible with a nitrile group on the $\mathrm{C}_{3}$-side chain of the indole $(5 \mathbf{b})$, electron-donating $(5 \mathbf{c})$ or electron-withdrawing $(5 \mathbf{d})$ groups or halogens $(\mathbf{5} \mathbf{e})$ on the benzene ring. In contrast to the electrolysis in presence of methanol, the dearomatized cis-products $\mathbf{5} \mathbf{f}-\mathbf{k}$ were also obtained from differently substituted $\mathrm{N}$-Ts tetrahydrocarbazoles or cyclopentaindole. Remarkably, it allows to create diastereoselectively two contiguous tetrasubstituted stereogenic centers. As for the dimethoxylation reaction, the diazidation proceeded without noticeable opening of the cyclopropyl ring in the case of $\mathbf{5} \mathbf{l}$. Finally, the formation of indoline $\mathbf{5 m}$, presumably cis, through diazidation of a steroid-derived indole demonstrates the versatility of this electrochemical protocol towards complex substrates bearing $\mathrm{C}-\mathrm{H}$ bonds prone to oxidation. ${ }^{13}$ Indeed, diazide-containing indolines $\mathbf{5}$ were poised to synthetic transformations. A double click reaction could be performed on $\mathbf{5}$ a with phenylacetylene yielding trans-bistriazole 6 and diazide $5 \mathrm{f}$ could be reduced to cis-2,3-diamine-containing indoline 7 (Scheme 2, E).

We next focused our attention to the mechanism of these dearomative difunctionalizations of indoles. No catalytic current was observed for TEMPO in presence of $\mathbf{1 a}$ by cyclic voltammetry (see SI). ${ }^{2 a}$ Moreover, the dearomative dimethoxylation of 1 could be performed without TEMPO in satisfactory yields. It is therefore unlikely that TEMPO acts as a mediator to directly oxidize the N-Ac indole $\mathbf{1}$ in the dimethoxylation reaction. ${ }^{14}$ The syntheses of $\mathbf{2 a c}$ and $\mathbf{5} \mathbf{l}$ represent radical clock experiments (Scheme 2, A and E). The fact that the cyclopropyl group at the $C_{3}$-position did not undergo ring opening for each reactions seems to indicate that a radical is probably not formed at the $\mathrm{C}_{3}$-position of the indole. Cyclic voltammetry experiments (see SI) suggest that methanol is involved in the reduction process at the cathode (see SI) liberating methoxide. ${ }^{15}$ In the diazidation reaction, the reduction process at the cathode is unclear to us, it is conceivable that adventitious water in the medium could react with $\mathrm{TMSN}_{3}$ and led to formation of protons which are reduced at the cathode. ${ }^{15}$ While NAc skatole ra is oxidized before methanol or $\mathrm{TMSN}_{3}$ (see SI), oxidative waves of methoxide or azide anions are observed at lower potentials than the oxidative wave of 1 (Scheme 3, A and SI). To verify if methoxy or azide radicals are responsible for the dimethoxylation or diazidation, these reactions were each conducted at a constant potential of $1.3 \mathrm{~V}$ ( $\mathrm{vs} \mathrm{Ag} / \mathrm{AgCl}$ ), between the oxidative waves of the methoxide or azide anions and the oxidative wave of $1 \mathbf{a}$ (Scheme 3, B). No reaction was observed in the dimethoxylation reaction, while a low yield of diazide 5a (23\%) was obtained along with recovered ra and unidentified byproducts. Moreover, replacing $\mathrm{TMSN}_{3}$ by $\mathrm{NaN}_{3}$ or $\mathrm{Bu}_{4} \mathrm{NN}_{3}$, which are well known to generate the azide radicals by anodic oxidation, resulted in no reaction.

Scheme 3. Mechanistic considerations. 


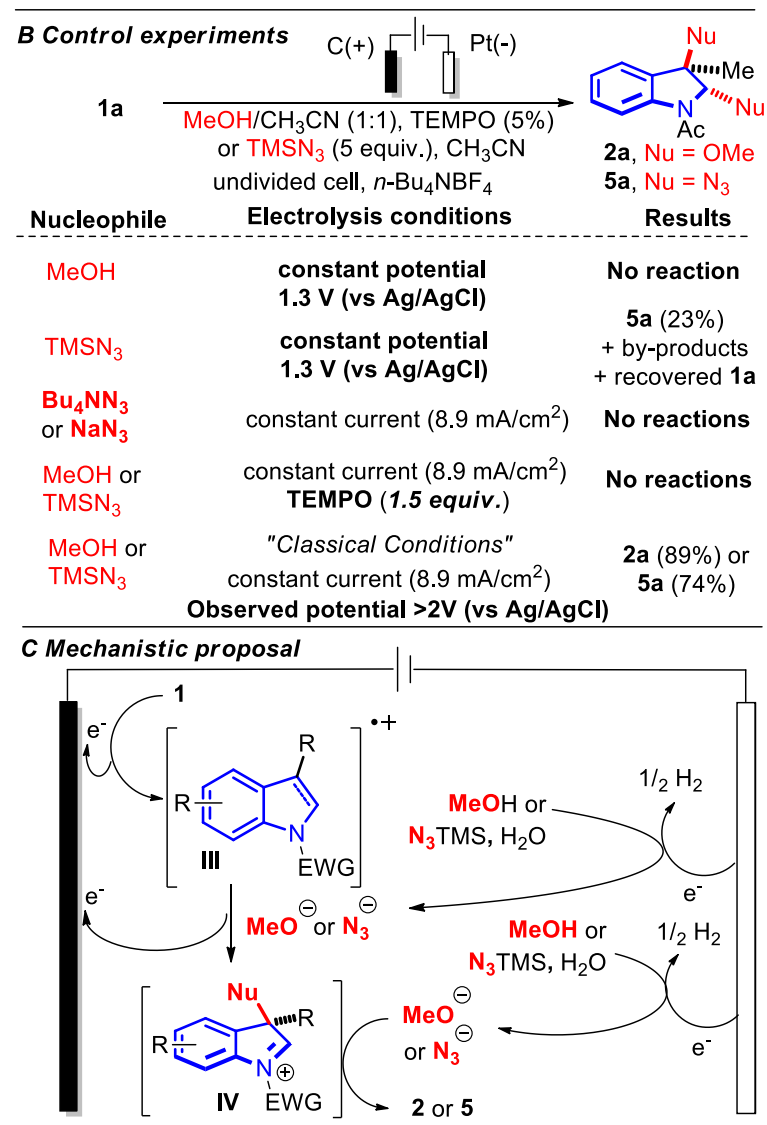

Interestingly, in presence of an excess of TEMPO, both the dialkoxylation and the diazidation did not proceed and only the starting N-Ac indole was recovered which is in sharp contrast to the azidooxygenation of alkenes developed recently by Lin which involved azide radicals. ${ }^{3 \mathrm{a}, \mathrm{d}, 16}$ More importantly, we noticed that in our classical constant current conditions, the potential of the anode was above $2 \mathrm{~V}$ (vs $\mathrm{Ag} / \mathrm{AgCl}$ ) for each reactions, which is superior to the oxidation potential of $12 .{ }^{17} \mathrm{We}$ therefore believe that $\mathrm{N}$-substituted indole $\mathbf{1}$ is oxidized di- rectly at the anode into radical cation intermediate III. Meth-

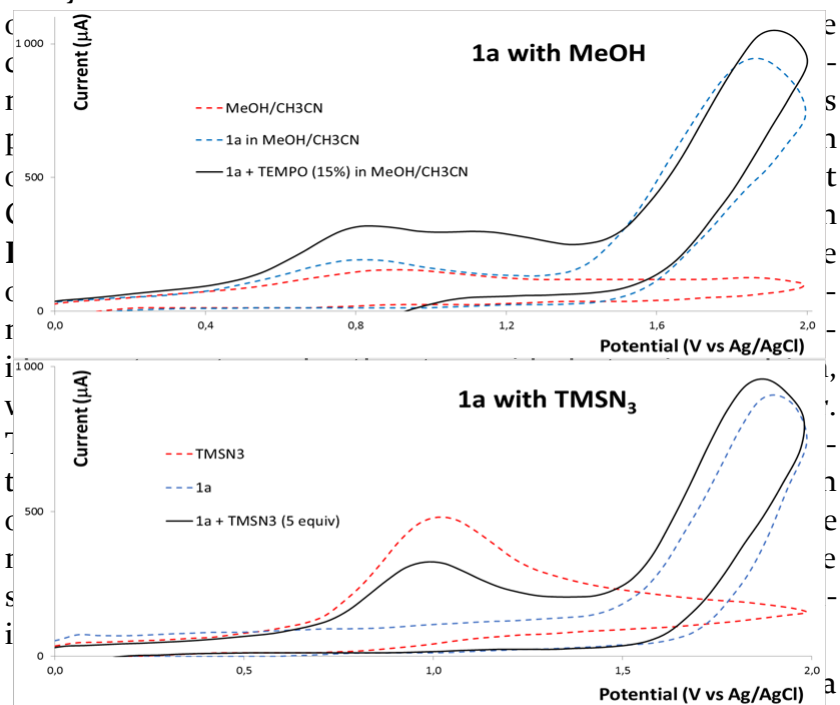

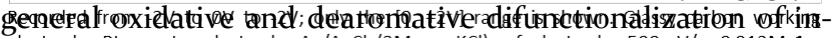

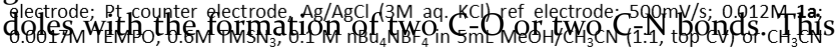
reatetion. likely proceeds via anodic oxidation of the N-substituted indole into a radical cation which could be trapped by alcohols or azide yielding three-dimensional 2,3-dialkoxyindolines or 2,3-diazidoindolines with a broad scope. These undivided electrolytic conditions avoid the use of an external oxidant and should inspire the development of other dearomatization reactions to access high added-value architectures from flat and readily available starting materials.

\section{ASSOCIATED CONTENT}

\section{Supporting Information}

The Supporting Information is available free of charge on the ACS Publications website.

Experimental procedures, characterizations and NMR spectra of all new compounds (PDF).

X-ray crystallographic data for 2f, 2y, 2al, 3e, 6 and 7 (cif).

\section{AUTHOR INFORMATION}

\section{Corresponding Author}

Guillaume.vincent@u-psud.fr

Notes

The authors declare no competing financial interests.

\section{ACKNOWLEDGMENT}

We gratefully acknowledge Dr. Laurence Grimaud (ENS Paris) and Dr. Maxime Vitale (Chimie Paris Tech) for helpful discussions. JW and YD thank the China Scholarship Council (CSC) for their respective $\mathrm{PhD}$ fellowships. We also gratefully acknowledge the ANR (ANR-17-CEo7-0050; "ArDCo"), the Université Paris Sud and the CNRS for financial support.

\section{REFERENCES}

(1) (a) McDonald, R. I.; Liu, G.; Stahl, S. S. Palladium(II)Catalyzed Alkene Functionalization via Nucleopalladation: Stereochemical Pathways and Enantioselective Catalytic Applications. Chem. Rev. 2011, 111, 2981-3019; (b) Lan, X.-W.; Wang, N.-X.; Xing, Y. Recent Advances in Radical Difunctionalization of Simple Alkenes. Eur. J. Org. Chem. 2017, 5821-5851. 
(2) (a) Francke, R.; Little, R. D. Redox Catalysis in Organic Electrosynthesis: Basic Principles and Recent Developments. Chem. Soc. Rev. 2014, 43, 2492-2521; (b) Horn, E. J.; Rosen, B. R.; Baran, P. S. Synthetic Organic Electrochemistry: An Enabling and Innately Sustainable Method. ACS Cent. Sci. 2016, 2, 302-308; (c) Yan, M.; Kawamata, Y.; Baran, P. S. Synthetic Organic Electrochemical Methods Since 2000: On the Verge of a Renaissance. Chem. Rev. 2017, 117, 13230-13319; (d) Yan, M.; Kawamata, Y.; Baran, P. S. Synthetic Organic Electrochemistry: Calling All Engineers. Angew. Chem. Int. Ed. 2018, 57, 41494155; (e) Wiebe, A.; Gieshoff, T.; Möhle, S.; Rodrigo, E.; Zirbes, M.; Waldvogel, S. R. Electrifying Organic Synthesis. Angew. Chem. Int. Ed. 2018, 57, 5594-5619; (f) Möhle, S.; Zirbes, M.; Rodrigo, E.; Gieshoff, T.; Wiebe, A.; Waldvogel, S. R. Modern Electrochemical Aspects for the Synthesis of Value-Added Organic Products. Angew. Chem. Int. Ed. 2018, 57, 6018-6041; (g) Jiang, Y.; Xu, K.; Zeng, C. Use of Electrochemistry in the Synthesis of Heterocyclic Structures. Chem. Rev. 2018, 118, 44854540; (h) Tang, S.; Liu, Y.; Lei, A. Electrochemical Oxidative Cross-Coupling with Hydrogen Evolution: A Green and Sustainable Way for Bond Formation. Chem 2018, 4, 27-45; (i) Kärkäs, M. D. Electrochemical Strategies for C-H Functionalization and C-N Bond Formation. Chem. Soc. Rev. 2018, 47, 5786-5865.

(3) (a) Fu, N.; Sauer, G. S.; Saha, A.; Loo, A.; Lin, S. Metal-Catalyzed Electrochemical Diazidation of Alkenes. Science 2017, 357, 575-579; (b) Fu, N.; Sauer, G. S.; Lin, S. Electrocatalytic Radical Dichlorination of Alkenes with Nucleophilic Chlorine Sources. J. Am. Chem. Soc. 2017, 139, 15548-15553; (c) Ye, K.-Y.; Pombar, G.; Fu, N.; Sauer, G. S.; Keresztes, I.; Lin, S. Anodically Coupled Electrolysis for the Heterodifunctionalization of Alkenes. J. Am. Chem. Soc. 2018, 140, 2438-2441; (d) Siu, J. C.; Sauer, G. S.; Saha, A.; Macey, R. L.; Fu, N.; Chauviré, T.; Lancaster, K. M.; Lin, S. Electrochemical Azidooxygenation of Alkenes Mediated by a TEMPO-N3 Charge-Transfer Complex. J. Am. Chem. Soc. 2018, 40, 12511-12520; (e) Fujimoto, K.; Tokuda, Y.; Matsubara, Y.; Maekawa, H.; Mizuno, T.; Nishiguchi, I. Regioselective Azidomethoxylation of Enol Ethers by Anodic Oxidation. Tetrahedron Lett. 1995, 36, 7483-7486; (f) Wang, Y.; Deng, L.; Mei, H.; Du, B.; Han, J.; Pan, Y. Electrochemical Oxidative Radical Oxysulfuration of Styrene Derivatives with Thiols and Nucleophilic Oxygen Sources. Green Chem. 2018, 20, 3444-3449; (g) Yan, W.; Lin, M.; Little, R. D.; Zeng, C.-C. Electrochemical Regioselective Azidoiodination of Alkenes. Tetrahedron 2017, 73, 764-770; (h) Li, L.; Luo, S. Electrochemical Generation of Diaza-Oxyallyl Cation for Cycloaddition in an All-Green Electrolytic System. Org. Lett. 2018, 20, 13241327; (i) Chiba, K.; Fukuda, M.; Kim, S.; Kitano, Y.; Tada, M. Dihydrobenzofuran Synthesis by an Anodic [3+2] Cycloaddition of Phenols and Unactivated Alkenes. J. Org. Chem. 1999, 64, 7654-7656; (j) Xiong, P.; Xu, H.-H.; Xu, H.-C. Metal- and Reagent-Free Intramolecular Oxidative Amination of Tri- and Tetrasubstituted Alkenes. J. Am. Chem. Soc. 2017, 139, 29562959; (k) Cai, C.-Y.; Xu, H.-C. Dehydrogenative Reagent-Free Annulation of Alkenes with Diols for the Synthesis of Saturated O-Heterocycles. Nat. Commun. 2018, 9, 3551; (l) Zhang, S.; Li, L.; Wu, P.; Gong, P.; Liu, R.; Xu, K. Substrate-Dependent Electrochemical Dimethoxylation of Olefins. Adv. Synth. Catal. doi:10.1002/adsc.201801173; (m) Liang, S.; Zeng, C.-C.; Luo, X.-G.; Ren, F.; Tian, H.-Y.; Sun, B.-G.; Little, R. D. Electrochemically Catalyzed Amino-Oxygenation of Styrenes: n$\mathrm{Bu}_{4} \mathrm{NI}$ Induced C-N Followed by a C-O Bond Formation Cascade for the Synthesis of Indolines. Green Chem. 2016, 18, 2222-2230; (n) Xu, H.-C.; Moeller, K. D. Intramolecular Anodic Olefin Coupling Reactions and the Synthesis of Cyclic Amines. J. Am. Chem. Soc. 2010, 132, 2839-2844.

(4) (a) Asymmetric Dearomatization Reactions; You, S.-L., Ed.; Wiley-VCH Verlag GmbH \& Co. KGaA, 2016; (b) Zheng, C.; You, S.-L. Catalytic Asymmetric Dearomatization by Transition-Metal Catalysis: A Method for Transformations of Aromatic Compounds. Chem 2016, 1, 830-857; (c) Zhuo, C.-X.;
Zhang, W.; You, S.-L. Catalytic Asymmetric Dearomatization Reactions. Angew. Chem. Int. Ed. 2012, 51, 12662-12686; (d) Roche, S. P.; Porco, J. A. Dearomatization Strategies in the Synthesis of Complex Natural Products. Angew. Chem. Int. Ed. 2011, 50, 4068-4093.

(5) Lovering, F.; Bikker, J.; Humblet, C. Escape from Flatland: Increasing Saturation as an Approach to Improving Clinical Success. J. Med. Chem. 2009, 52, 6752-6756.

(6) (a) Roche, S. P.; Youte Tendoung, J.-J.; Tréguier, B. Advances in Dearomatization Strategies of Indoles. Tetrahedron 2015, 71, 3549-3591; (b) Denizot, N.; Tomakinian, T.; Beaud, R.; Kouklovsky, C.; Vincent, G. Synthesis of 3-Arylated Indolines from Dearomatization of Indoles. Tetrahedron Lett. 2015, 56, 4413-4429

(7) (a) Lachkar, D.; Denizot, N.; Bernadat, G.; Ahamada, K.; Beniddir, M. A.; Dumontet, V.; Gallard, J.-F.; Guillot, R.; Leblanc, K.; N'nang, E. O.; et al. Unified Biomimetic Assembly of Voacalgine A and Bipleiophylline via Divergent Oxidative Couplings. Nat. Chem. 2017, 9, 793-798; (b) Denizot, N.; Pouilhès, A.; Cucca, M.; Beaud, R.; Guillot, R.; Kouklovsky, C.; Vincent, G. Bioinspired Direct Access to Benzofuroindolines by Oxidative [3+2] Annulation of Phenols and Indoles. Org. Lett. 2014, 16, 5752-5755; (c) Tomakinian, T.; Guillot, R.; Kouklovsky, C.; Vincent, G. Direct Oxidative Coupling of NAcetyl Indoles and Phenols for the Synthesis of Benzofuroindolines Related to Phalarine. Angew. Chem. Int. Ed. 2014, 53, 11881-11885; (d) Marques, A.-S.; Coeffard, V.; Chataigner, I.; Vincent, G.; Moreau, X. Iron-Mediated Domino Interrupted Iso-Nazarov/Dearomative $(3+2)$-Cycloaddition of Electrophilic Indoles. Org. Lett. 2o16, 18, 5296-5299; (e) Ryzhakov, D.; Jarret, M.; Guillot, R.; Kouklovsky, C.; Vincent, G. RadicalMediated Dearomatization of Indoles with Sulfinate Reagents for the Synthesis of Fluorinated Spirocyclic Indolines. Org. Lett. 2017, 19, 6336-6339; (f) Wu, J.; Nandi, R. K.; Guillot, R.; Kouklovsky, C.; Vincent, G. Dearomative Diallylation of NAcylindoles Mediated by $\mathrm{FeCl}_{3}$. Org. Lett. 2018, 20, 1845-1848.

(8) Electrochemical dearomatization of indoles: (a) Liu, K.; Tang, S.; Huang, P.; Lei, A. External Oxidant-Free Electrooxidative $\left[3^{+2}\right]$ Annulation between Phenol and Indole Derivatives. Nat. Commun. 2017, 8, 775; (b) Ding, H.; DeRoy, P. L.; Perreault, C.; Larivée, A.; Siddiqui, A.; Caldwell, C. G.; Harran, S.; Harran, P. G. Electrolytic Macrocyclizations: Scalable Synthesis of a Diazonamide-Based Drug Development Candidate. Angew. Chem. Int. Ed. 2015, 54, 4818-4822; (c) Yin, B.; Wang, L.; Inagi, S.; Fuchigami, T. Electrosynthesis of fluorinated indoles derivatives. Tetrahedron 2010, 66, 6820-6825; electrochemical dearomatization of phenols: (d) Lipp, A.; Ferenc, D.; Gütz, C.; Geffe, M.; Vierengel, N.; Schollmeyer, D.; Schäfer, H. J.; Waldvogel, S. R.; Opatz, T. A Regio- and Diastereoselective Anodic Aryl-Aryl Coupling in the Biomimetic Total Synthesis of (-)-Thebaine. Angew. Chem. Int. Ed. 2018, 57, 11055-11059; (e) Barjau, J.; Schnakenburg, G.; Waldvogel, S. R. DiversityOriented Synthesis of Polycyclic Scaffolds by Modification of an Anodic Product Derived from 2,4-Dimethylphenol. Angew. Chem. Int. Ed. 2011, 5o, 1415-1419; (f) Yamamura, S.; Nishiyama, S. Anodic Oxidation of Phenols Towards the Synthesis of Bioactive Natural Products. Synlett 2002, 0533-0543; electrochemical dearomatization of furans: (g) Wu, H.; Moeller, K. D. Anodic Coupling Reactions: A Sequential Cyclization Route to the Arteannuin Ring Skeleton. Org. Lett. 2007, 9, 4599-4602; (h) Miller, A. K.; Hughes, C. C.; KennedySmith, J. J.; Gradl, S. N.; Trauner, D. Total Synthesis of (-)Heptemerone B and (-)-Guanacastepene E. J. Am. Chem. Soc. 2006, 128, 17057-17062.

(9) Royer reported the anodic oxidation of few tetrahydro- $\beta$-carbolines in presence of methanol and in one case observed the formation of an intermediate dearomatized dimethoxyindoline: Royer, J.; Planas, L.; Martens, T.; Billon-Souquet, F. Anodic Oxidation of Tetrahydro-b-Carboline Derivatives: Formal Oxidation of Protonated Tertiary Amines. Heterocycles 2004, 63, 765-771. 
(10) (a) Kwon, S.; Kuroki, N. Reaction of 1-Substituted Indoles with Carboxylic Acids and N-Iodosuccinimide. Chem. Lett. 1980, 9 , 237-238; (b) Vice, S. F.; Dmitrienko, G. I. The BrominationMethanolysis of N-Acetyl-2,3-Dimethylindole. Can. J. Chem. 1982, 6o, 1233-1237; (c) Kawasaki, T.; Chien, C.-S.; Sakamoto, M. Oxidation of 1-Acylindoles with Molybdenum Peroxo Complex $\left(\mathrm{MoO}_{5} \mathrm{HMPA}\right)$ : Preparation of 1-Acyl-Trans- and Cis2,3-Dihydroxyindoline Derivatives. Chem. Lett. 1983, 12, 855858; (d) Takayama, H.; Misawa, K.; Okada, N.; Ishikawa, H.; Kitajima, M.; Hatori, Y.; Murayama, T.; Wongseripipatana, S.; Tashima, K.; Matsumoto, K.; et al. New Procedure to Mask the $2,3-\pi$ Bond of the Indole Nucleus and Its Application to the Preparation of Potent Opioid Receptor Agonists with a Corynanthe Skeleton. Org. Lett. 2oo6, 8, 5705-5708; (e) Silva Jr, L. F.; Craveiro, M. V.; Gambardella, M. T. P. Synthesis of Polyalkylated Indoles Using a Thallium(III)-Mediated Ring-Contraction Reaction. Synthesis 2007, 3851-3857; (f) Liu, Q.; Zhao, Q. Y.; Liu, J.; Wu, P.; Yi, H.; Lei, A. A Trans Diacyloxylation of Indoles. Chem. Commun. 2012, 48, 3239-3241.

(11) (a) Büchi, G.; Manning, R. E. Chemical Transformations of Ibogaine. J. Am. Chem. Soc. 1966, 88, 2532-2535; (b) Higuchi, K.; Tayu, M.; Kawasaki, T. Active Thionium Species Mediated Functionalization at the $2 \alpha$-Position of Indole Derivatives. Chem. Commun. 2011, 47, 6728-6730; (c) Zaimoku, H.; Hatta, T.; Taniguchi, T.; Ishibashi, H. Iodine-Mediated $\alpha$-Acetoxylation of 2,3-Disubstituted Indoles. Org. Lett. 2012, 14, 6o886091; (d) Nakano, Y.; Lupton, D. W. Palladium[II] Catalysed C(Sp3)-H Oxidation of Dimethyl Carbamoyl Tetrahydrocarbazoles. Chem. Commun. 2014, 50, 1757-176o; (e) Jiang, L.; Xie, X.; Zu, L. Tert-Butyl Hypochlorite Mediated Diastereoselective Oxidative Coupling: Access to 1-Functionalized Tetrahydrocarbazoles. RSC Adv. 2015, 5, 9204-9207; (f) Klussmann, M.; Gulzar, N. Process for Preparing Substituted Indole Derivatives. WO/2014/o16296, January 31, 2014.

(12) (a) Nocquet-Thibault, S.; Rayar, A.; Retailleau, P.; Cariou, K.; Dodd, R. H. Iodine(III)-Mediated Diazidation and Azido-Oxyamination of Enamides. Chem. - Eur. J. 2015, 21, 14205-14210; (b) Yuan, Y.-A.; Lu, D.-F.; Chen, Y.-R.; Xu, H. Iron-Catalyzed Direct Diazidation for a Broad Range of Olefins. Angew. Chem. Int. Ed. 2016, 55, 534-538; (c) Shen, S.-J.; Zhu, C.-L.; Lu, D.-F.; $\mathrm{Xu}, \mathrm{H}$. Iron-Catalyzed Direct Olefin Diazidation via Peroxyester Activation Promoted by Nitrogen-Based Ligands. ACS Catal. 2018, 8, 4473-4482; for earlier reports on dearomative diazidation of indoles: (d) Tamura, Y.; Kwon, S.; Tabusa, F.; Ikeda, M. Reaction of Iodine Azide with 1-Acylindoles: Formation of 1-Acyl-Cis- and Trans-2,3-Diazidoindolines. Tetrahedron Lett. 1975, 16, 3291-3294; (e) Tamura, Y.; Chun, M. W.;
Kwon, S.; Said, M. B.; Okada, T.; Ikeda, M. Reaction of Benzo[b]Furan and 1-Acylindoles with Iodine Azide. Chem. Pharm. Bull. 1978, 26, 3515-3520; (f) Moriarty, R. M.; Khosrowshahi, J. S. A Versatile Synthesis of Vicinal Diazides Using Hypervalent Iodine. Tetrahedron Lett. 1986, 27, 2809-2812.

(13) Isolated with $4 \%$ of dearomatized triazide $\mathbf{5 n}$ and $4 \%$ of alpha azidation product 8 . The former arises from azidation of one of the $\mathrm{C}-\mathrm{H}$ bond $\left(\mathrm{C}_{5}\right.$ or $\left.\mathrm{C} 6\right)$ of the indole nucleus of $5 \mathbf{m}$, while the latter may arise from $\mathbf{5} \mathbf{m}$ through an elimination similar to scheme $2 \mathrm{~B}$.

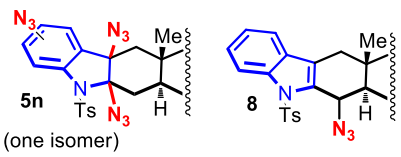

(14) It is unclear to us how the addition of a small amount of TEMPO slightly increase the yield and avoid decomposition of $\mathbf{1}$. It might prevent the increase of the potential at the anode and therefore the decomposition of 1 at the end of the reaction when the concentration of $\mathbf{1}$ is too low.

(15) In both reactions, gas evolution is observed at the cathode, which we believe is hydrogen produced by the reduction of methanol or adventitious water. In the diazidation, hexamethyldisilane was not detected by NMR when deuterated acetonitrile was used as solvent, therefore $\mathrm{TMSN}_{3}$ is probably not directly reduced at the cathode.

(16) If a $\mathrm{N}_{3}$ radical was adding first to the indole, we would have expected the trapping of the resulting carbon radical with TEMPO (see ref 3a,d) which is not the case (Scheme 3, B). It is likely that TEMPO is oxidized instead of $\mathbf{1 a}$ and the resulting excess oxoammonium ion could react with methanol or $\mathrm{TMSN}_{3}$

(17) Indeed, the potential at the anode is quite high and could lead to side reactions. However, we have shown a reasonable functional groups compatibility during the present study.

(18) The electrolysis of 2-cyclopropyl-N-Ts-indole with $\mathrm{MeOH}$ led to an intricate mixture of compounds with small amounts of indole $9(5 \%)$ which results from the opening of the cyclopropyl by methanol. This result may suggest the existence of a radical intermediate at $\mathrm{C}_{2}$ and a step-wise process for the formation of IV from III.

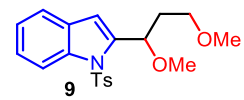




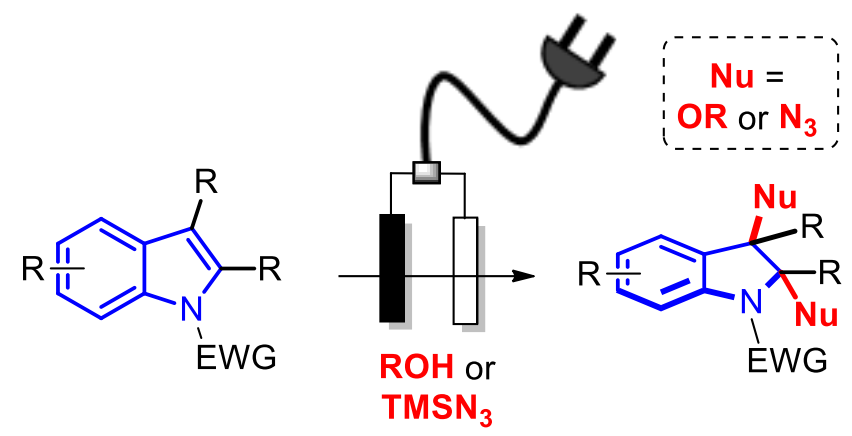

7 